\title{
PERCEPÇÃO DE DIABÉTICOS E PAPEL DOS PROFISSIONAIS DE SAÚDE SOBRE A EDUCAÇÃO AMBIENTAL DE RESÍDUOS PERFUROCORTANTES PRODUZIDOS EM DOMICÍLIOS
}

\author{
Simone Aquino ${ }^{1}$ \\ Maria Antonietta Leitão Zajac ${ }^{2}$ \\ Cláudia Terezinha Kniess ${ }^{3}$
}

Resumo: Os resíduos de saúde recebem diferentes classificações, sendo os materiais perfurocortantes, como agulhas e lancetas, pertencentes ao grupo $\mathrm{E}$. O uso doméstico de seringas, agulhas e lancetas é uma realidade dos portadores de Diabetes Mellitus, que dependem de insulina e descartam erroneamente os perfurocortantes junto aos resíduos sólidos comuns. A educação sobre a segregação e disposição adequada dos resíduos do grupo $E$, gerados nos domicílios, deve envolver vários profissionais da saúde, seja do setor público ou privado. O presente estudo teve como objetivo analisar a percepção de diabéticos insulinodependentes sobre a responsabilidade ambiental da geração de seu resíduo e avaliar o papel dos stakeholders da saúde envolvidos na educação ambiental, na cidade de São Paulo, sobre a logística reversa de resíduos perfurocortantes. A revenda pequena de recipiente de coleta para resíduos $\mathrm{E}$ nas farmácias, a falta de conscientização sobre o descarte correto dos diabéticos e poucas campanhas educacionais sobre a logística reversa nas UBS ainda são pontos fracos a serem melhorados na educação ambiental de geradores de resíduos $\mathrm{E}$ em domicílios.

Palavras-chave: Resíduo E; Diabetes; Domicílios; Educação. ambiental
${ }^{1}$ Universidade Nove de Julho. E-Mail: siaq06@hotmail.com

2 Faculdades Oswaldo Cruz. E-Mail: m.a.leitao@zipmail.com.br

${ }^{3}$ Universidade Nove de Julho. E-Mail: kniesscl@gmail.com

Revbea, São Paulo, V. 14, № 1: 186-206, 2019. 


\section{Introdução}

Resíduos do tipo E são materiais como lancetas, agulhas, seringas agulhadas, etc., sendo proibido reencapar ou proceder a retirada de agulhas manualmente. De acordo com a Agência Nacional de Vigilância Sanitária (ANVISA) definem-se como geradores de RSS, todos os serviços relacionados com o atendimento à saúde humana ou animal, inclusive os serviços de assistência domiciliar e de trabalhos de campo (BRASIL, 2004).

Ainda a Norma Brasileira Regulamentadora (NBR) № 10004, publicada pela Associação Brasileira de Normas Técnicas (ABNT, 2004), define resíduos sólidos como resíduos nos estados sólido e semissólido, que resultam de atividades de origem industrial, doméstica, hospitalar, comercial, agrícola, de serviços e de varrição. Ainda classifica os resíduos quanto aos riscos potenciais ao meio ambiente e à saúde pública. A NBR no 12.808 e oㅜ 12.807 de 1993, classificam e definem os Resíduos de Serviços de Saúde (RSS), que recebem um tratamento diferenciado do lixo comum, havendo regras estipuladas a serem seguidas pelos geradores dos resíduos (ABNT, 1993; MAROUNM, 2006).

A Resolução da Diretoria Colegiada (RDC) no 306 da Agência Nacional de Vigilância Sanitária (ANVISA) e Resolução do Conselho Nacional do Meio Ambiente (CONAMA) № 358, estabeleceram que a produção destes resíduos especiais tivessem uma disposição final segura e diferenciada, de forma eficiente, visando a proteção dos trabalhadores, a preservação da saúde pública, dos recursos naturais e do meio ambiente (BRASIL, 2004; CONAMA, 2005). A partir do ano de 2018, a RDC no 222 publicada pela ANVISA manteve a definição dos grupos de resíduos A, B, C, D e E como (BRASIL, 2018):

[...] resíduos de serviços de saúde do Grupo A: resíduos com a possível presença de agentes biológicos que, por suas características, podem apresentar risco de infecção, elencados no Anexo I desta Resolução; resíduos de serviços de saúde do Grupo B: resíduos contendo produtos químicos que podem apresentar risco à saúde pública ou ao meio ambiente, dependendo de suas características de inflamabilidade, corrosividade, reatividade e toxicidade, elencados no Anexo I desta Resolução; resíduos de serviços de saúde do Grupo C: rejeitos radioativos, elencados no Anexo I desta Resolução; resíduos de serviços de saúde do Grupo D: resíduos que não apresentam risco biológico, químico ou radiológico à saúde ou ao meio ambiente, podendo ser equiparados aos resíduos domiciliares, elencados no Anexo I desta Resolução; resíduos de serviços de saúde do Grupo E: resíduos perfurocortantes ou escarificantes, tais como: lâminas de barbear, agulhas, escalpes, ampolas de vidro, brocas, limas endodônticas, fios ortodônticos cortados, próteses bucais metálicas inutilizadas, pontas diamantadas, lâminas de bisturi, lancetas, tubos capilares, micropipetas, lâminas e lamínulas, espátulas e todos os utensílios de vidro quebrados no laboratório 
(pipetas, tubos de coleta sanguínea e placas de Petri), elencados no Anexo I desta Resolução.

Os materiais perfurocortantes (grupo E) devem ser descartados após o uso em recipientes, rígidos, resistentes à punctura, ruptura e vazamento, com tampa, devidamente identificados, atendendo aos parâmetros referenciados na norma NBR $\mathrm{n}^{\circ} 13853$ (ABNT, 1997), sendo expressamente proibido o esvaziamento desses recipientes para o seu reaproveitamento.

Percebe-se que os órgãos de fiscalização estabelecem normas aos estabelecimentos de interesse à saúde, geradores de RSS, mas não abrange a educação da população ou comunidade geradora de resíduos $\mathrm{E}$ em ambiente domiciliar, ou seja, não há um sistema de coleta diferenciado destes resíduos em domicílios e tampouco campanhas de informação claras para diabéticos. Tal preocupação se justifica pela implantação de processos de segregação dos diferentes tipos de resíduos, em sua fonte e no momento de sua geração, o que conduz certamente à minimização de resíduos, em especial àqueles que requerem um tratamento prévio à disposição final (ANVISA, 2006).

De acordo com a American Diabetes Association (ADA) o modo recomendado de acondicionar seringas e agulhas no domicílio seria fazê-lo em recipientes apropriados ou, na falta desses, em recipientes rígidos, com abertura larga e tampa (ADA, 2007, BRASIL, 2004). Mesmo assim, ainda há o problema do descarte do RSS com o resíduo doméstico, o que faz com que esse material seja descartado em aterros sanitários ou lixões, oferecendo riscos à saúde de garis, coletores de lixo, da população e ao ambiente.

Portanto, a justificativa do presente estudo, se refere à educação dada aos diabéticos sobre os resíduos perfurocortantes gerados em domicílio e que devem ser agrupados, segregados, acondicionados e destinados de forma diferenciada para que não causem danos à saúde da população e tampouco agridam o meio ambiente. Os resíduos perfurocortantes (E) são gerados em domicílios por usuários de insulina que utilizam seringas, agulhas e lancetas (pontas agulhadas para controle glicêmico), mas que não estão claramente incluídos em um sistema de coleta domiciliar por órgãos públicos ou por incentivos ou campanhas de logística reversa em parcerias com farmácias e drogarias, que vendem os recipientes de coleta de resíduo E. Portanto, a questão de pesquisa proposta a ser respondida é: Como os stakeholders da área da saúde atuam na educação sobre a destinação correta de resíduo do tipo $\mathrm{E}$, gerados em domicílios por diabéticos, na cidade de São Paulo?

O objetivo proposto no presente estudo é compreender qual a percepção dos próprios diabéticos sobre a geração de resíduo $\mathrm{E}$ em seu domicílio e qual o apoio prestado pelos profissionais de Unidades Básicas de Saúde (UBS) e farmácias, quanto à educação ambiental sobre a Logística Reversa (LR) de seringas e lancetas geradas em ambiente doméstico, na cidade de São Paulo. 


\section{Legislação sobre Resíduos de Saúde}

A Lei 9.605 de 1998, Lei de Crimes Ambientais, estabelece sanções para quem praticar condutas e atividades lesivas ao meio ambiente, o que engloba 0 gerenciamento inadequado de resíduos sólidos (BRASIL, 1998). De acordo com Marounm (2006) a classificação dos resíduos sólidos gerados em uma determinada atividade é o primeiro passo para estruturar um plano de gestão adequado. Com relação aos RSS é importante salientar que das 149.000 toneladas de resíduos residenciais e comerciais geradas diariamente, apenas uma fração inferior a $2 \%$ é composta por RSS e, destes, apenas 10 a $25 \%$ necessitam de cuidados especiais. Entretanto, os RSS são parte importante do total de resíduos sólidos urbanos, não necessariamente pela quantidade gerada (cerca de $1 \%$ a $3 \%$ do total), mas pelo potencial de risco que representam à saúde e ao meio ambiente. Os RSS são classificados em função de suas características e consequentes riscos que podem acarretar ao meio ambiente e à saúde (ANVISA, 2006).

A partir da classificação é possível definir as etapas de coleta, armazenagem, transporte, manipulação e destinação final, de acordo com cada tipo de resíduo gerado. A discussão sobre o sistema de LR nas diferentes cadeias produtivas surgiu com ênfase após a publicação da Política Nacional de Resíduos Sólidos (PNRS), sancionada pela Lei no 12.305 (BRASIL, 2010) e que definiu os princípios, diretrizes, objetivos, instrumentos e distribuição de responsabilidades para a gestão dos resíduos sólidos no país. Na ausência de uma diretriz na PNRS, as normas técnicas brasileiras relativas ao gerenciamento de resíduos sólidos, publicadas pela ABNT, são amplamente adotadas em nosso país (MAROUNM, 2006).

São considerados oficialmente como geradores de RSS os laboratórios analíticos de produtos para saúde; necrotérios, funerárias e serviços onde se realizem atividades de embalsamamento; serviços de medicina legal; drogarias e farmácias inclusive as de manipulação; estabelecimentos de ensino e pesquisa na área de saúde; centros de controle de zoonoses; distribuidores de produtos farmacêuticos, importadores, distribuidores e produtores de materiais e controles para diagnóstico in vitro; unidades móveis de atendimento à saúde; serviços de acupuntura; serviços de tatuagem, dentre outros similares (BRASIL, 2004; 2018).

O gerenciamento deve abranger todas as etapas de planejamento dos recursos físicos, dos recursos materiais e da educação dos recursos humanos envolvidos no manejo dos RSS (BRASIL, 2004). Todo gerador de RSS deve elaborar um Plano de Gerenciamento de Resíduos de Serviços de Saúde (PGRSS), compatível com as normas locais relativas à coleta, transporte e disposição final dos resíduos gerados nos serviços de saúde, estabelecidas pelos órgãos locais responsáveis por estas etapas. O manejo dos RSS é entendido como a ação de gerenciar os resíduos em seus aspectos intra e extraestabelecimento, desde a geração até a disposição final (BRASIL, 2004; 2018). 
Os resíduos de serviços de saúde são considerados apenas aqueles provenientes de hospitais, clínicas médicas e outros grandes geradores. Entretanto, resíduos de natureza semelhante são produzidos por geradores bastante variados (TAPIA, 2009).

\section{Diabéticos e a geração de resíduos $\mathrm{E}$}

Azevedo et al. (2017) afirmaram que a Educação Ambiental (EA) é uma ferramenta estratégica para se mudar o rumo da história e sensibilizar os indivíduos na direção de uma consciência ecológica. Entretanto, conhecer os indivíduos e seu papel no meio ambiente tem muitas vertentes, a exemplo dos diabéticos que dependem de insulina na forma injetável.

A doença diabetes representa um problema de saúde pública mundial. É uma doença sistêmica crônico-degenerativa, caracterizados por hiperglicemia crônica (elevada concentração de glicose no sangue), devido à deficiência na produção ou ação da insulina (BARBOSA, 1999) e está entre as doenças que produzem uma grande quantidade de resíduo de saúde. Os indivíduos portadores de Diabetes Mellittus insulinodependentes (DM tipo 1) são importantes produtores de resíduos sólidos de saúde (TAPIA, 2009).

Segundo Maia e Araújo (2004) o método mais utilizado para administração de insulina, foi o uso de seringa convencional em $50 \%$ dos casos. De acordo com Zanetti et al. (2001) em um estudo realizado com crianças diabéticas, foi observado que os materiais utilizados por mães em suas residências para o controle do diabetes infantil foram: algodão, álcool, seringa, agulha (73,3\%); algodão, álcool, seringa, agulha e fitas reagentes $(16,7 \%)$; algodão, álcool, seringa, agulha e glucometer (6,7\%) e algodão, álcool, seringa, agulha e vitajet (bomba de insulina) (3,3\%).

Portanto, os diabéticos geram em seus domicílios resíduos que também seriam classificados pela ANVISA como RSS, decorrentes da aplicação de insulina e monitoramento do nível glicêmico, com uso de lancetas (agulhas de punção) e equipamento para dosagem de glicose sanguínea. Na realidade, os usuários de insulina geram no mesmo resíduo mais de um tipo de RSS, como de origem biológica (sangue-A), química (insulina -B) e do tipo perfurocortante (seringas agulhadas e lancetas-E), o que requer maior atenção sobre a educação ambiental advinda dos profissionais que atuam em programas de Estratégia de Saúde da Família (ESF), pelos riscos tanto para os usuários, familiares e coletores de resíduos urbanos quanto para o ambiente (TAPIA, 2009).

De acordo com André e colaboradores (2012), o número crescente de diabéticos acarreta uma maior geração de resíduos $\mathrm{E}$, biológicos e químicos em domicílios. A ausência de diretriz ou orientação técnica e legal a respeito desses resíduos gerados em domicílios favorece o acondicionamento e disposição final inadequada para o meio ambiente. Ainda de acordo com os autores, as diferentes práticas de descarte de seringas utilizadas para a aplicação de 
insulina em distintas regiões brasileiras e em outros países, como a Inglaterra, ocorrem devido às diferenças socioeconômicas e culturais apresentadas em cada contexto.

Não há para os diabéticos orientações evidentes quanto ao resíduo gerado em seus domicílios e, na maioria das vezes, nem é um assunto abordado nas consultas médicas. Porém, não está claro (nos programas de acompanhamento de diabéticos insulinodependentes) como os resíduos provenientes do autocuidado devem ser descartados ou se os portadores recebem os recipientes adequados, para posterior coleta nos postos de atendimento à atenção básica de saúde.

Segundo André (2012) considerando o elevado número de pessoas com DM no Brasil, e que, dentre esses indivíduos, 20 a $25 \%$ são usuários de insulina, em tratamento ambulatorial e domiciliar, faz-se necessária a existência de um sistema organizado para a educação sobre o manejo desse tipo de resíduo no domicílio. Os RSS podem causar danos à saúde e ao ambiente se não houver uma destinação segura e adequada.

No Brasil, os serviços de saúde devem seguir as recomendações técnicas e legais definidas pela ANVISA e CONAMA, que incluem os resíduos gerados pelos serviços de assistência domiciliar (Home care), determinando que estes devam ser acondicionados e recolhidos pelos próprios agentes de atendimento ou por pessoa treinada para a atividade e encaminhados ao estabelecimento de saúde de referência. Os recipientes (padrão caixa de papelão amarela) devem estar identificados de acordo com símbolo internacional de risco biológico, acrescido da inscrição de "PERFUROCORTANTE" e os riscos adicionais, químico ou radiológico (BRASIL, 2004; 2018).

O volume do recipiente de acondicionamento (uma caixa de papelão amarela conhecida pela marca Descarpack) deve ser compatível com a geração diária deste tipo de resíduo. Os recipientes mencionados devem ser descartados quando o preenchimento atingir $2 / 3$ de sua capacidade ou o nível de preenchimento ficar a 5 (cinco) $\mathrm{cm}$ de distância da boca do recipiente, sendo proibido o seu esvaziamento ou reaproveitamento (BRASIL, 2004; 2018).

André (2012) reportou que há uma inadequação do manejo e descarte dos resíduos oriundos do tratamento e monitoramento do DM no domicílio de usuários de insulina, alertando para a necessidade de ampliar as ações educativas em saúde com vistas à geração de resíduos perfurocortantes e de origem química e biológica nos domicílios de usuários de insulina, no sentido de minimizar riscos de exposição a esses agentes ambientais. Ainda de acordo com um estudo realizado por com Zanetti et al. (2001) foi apontado que 13,3\% das mães de crianças diabéticas, aprenderam sobre a autoaplicação de insulina com auxiliares de enfermagem. Dentro da equipe multiprofissional, o enfermeiro é responsável pelo desenvolvimento de programas de treinamento e educação relativos ao cuidado domiciliar da pessoa diabética, incluída a técnica de autoaplicação de insulina. 
Há uma tendência das pessoas, independentemente da formação, nível cultural e posição na sociedade, em não perceberem os riscos existentes nos resíduos domiciliares, já que os mesmos são normalmente classificados como "resíduos comuns". Isto pode ser confirmado observando-se os poucos investimentos que são feitos para melhorar os sistemas de coleta e de disposição final dos resíduos urbanos, predominando os lixões como forma de disposição final dos resíduos, além da permissividade da existência de catadores, que não têm amparo social algum (CUSSIOL et al., 2006).

Segundo um estudo de Silva et al. (2012) 100\% dos pacientes com DM estudados acondicionavam e destinavam de forma incorreta os RSS gerados em domicílios, em sacolas de plásticos misturados aos resíduos sólidos domiciliares, sem nenhum cuidado. No Brasil, os resultados das análises microbiológicas em amostras de resíduos de serviços de saúde e domiciliar apontam para uma razoável semelhança entre eles, a ponto de permitir colocá-los, do ponto de vista gerencial, em uma mesma categoria de risco (CUSSIOL et al., 2006).

Portanto, a implantação de programas educativos sobre os processos de segregação dos diferentes tipos de resíduos em sua fonte e no momento de sua geração conduz certamente à minimização de resíduos, em especial àqueles que requerem um tratamento prévio à disposição final. Nos resíduos onde predominam os riscos biológicos, deve-se considerar o conceito de cadeia de transmissibilidade de doenças, que envolve características do agente agressor, tais como capacidade de sobrevivência, virulência, concentração e resistência, da porta de entrada do agente às condições de defesas naturais do receptor (ANVISA, 2006).

Como visto, a ANVISA define os RSS como resíduos gerados e decorrentes de ações e procedimentos de cuidados à saúde apenas para grandes estabelecimentos de saúde geradores e não dispõe de regulamentação para a educação e gerenciamento de resíduo $\mathrm{E}$ doméstico, ou seja, diabéticos que utilizam seringas para autoaplicação de insulina ou lancetas para o controle glicêmico, em sua residência, que se enquadrariam como geradores de RSS, mas seu resíduo não é controlado ou monitorado, ficando o resíduo $E$ ou perfurocortantes contaminados (agulhas, seringas e lancetas usadas) gerados em domicílio à margem da coleta adequada realizada em estabelecimentos de saúde.

\section{Materiais e Métodos}

O projeto de pesquisa, relacionado ao estudo apresentado, foi submetido ao Comitê de Ética da Instituição de Ensino Superior e registrado na Plataforma Brasil com parecer consubstanciado de aprovação de ํㅜ 1.249.058. Trata-se de um estudo de abordagem mista, de natureza descritiva e exploratória, conduzido em três etapas envolvendo diferentes atores do fenômeno estudado, visto que os trabalhos de natureza qualitativa permitem uma compreensão dos agentes envolvidos, sem buscar a regularidade, mas sim as motivações para suas ações (GODOI; BALSINI, 2010). 
$\mathrm{Na}$ primeira fase foi realizado um levantamento sobre os pontos de revenda de recipientes de coleta de resíduo $E$ (padrão ABNT) e para isso foram selecionadas 135 farmácias e 100 drogarias $(n=235)$ distribuídas, nas zonas Sul, Norte, Sudeste e Oeste da cidade de São Paulo no período de janeiro de 2014 a janeiro de 2016, sendo uma amostragem considerada não probabilística e por conveniência. Em uma segunda fase, um levantamento realizado em janeiro de 2015 a janeiro de 2016, junto aos profissionais de saúde de 70 Unidades Básica de Saúde (UBS) $(n=70)$. O levantamento de UBSs foi elaborado a partir do site da Secretaria Municipal de Saúde de São Paulo e a escolha das unidades foi também aleatória e por conveniência. Foi aplicado um questionário elaborado com perguntas semiestruturadas, sobre a distribuição de caixas coletoras, educação e logística reversa de resíduos $\mathrm{E}$, provenientes dos domicílios dos diabéticos. Na terceira etapa, uma pesquisa eletrônica do tipo Survey foi realizada no período de agosto de 2014 a agosto de 2016 com a aplicação de um roteiro semiestruturado de questões referentes ao tema. Para 220 diabéticos insulinodependentes.

A pesquisa baseou-se na aplicação de um questionário aplicado a cada grupo dos stakeholders, sobre seu papel na educação e logística reversa em pontos de coletas na cidade de São Paulo, com um roteiro de perguntas semiestruturadas, baseadas em um construto teórico (Tabela 1).

Tabela 1: Construto de pressupostos teóricos para roteiro semiestruturado das questões aplicadas nas entrevistas.

\begin{tabular}{|c|c|c|}
\hline Roteiro de perguntas Farmácias/ Drogarias & Pressupostos teóricos & Referências \\
\hline $\begin{array}{l}\text { 1. Seu estabelecimento vende/fornece insulina } \\
\text { para diabéticos tipo 1? }\end{array}$ & \multirow{10}{*}{$\begin{array}{l}\text { Os resíduos do grupo } \mathrm{E} \\
\text { devem ser descartados } \\
\text { em recipientes de } \\
\text { paredes rígidas, } \\
\text { resistentes à punctura e } \\
\text { vazamento, com tampa e } \\
\text { identificados com o } \\
\text { símbolo internacional de } \\
\text { risco biológico, acrescido } \\
\text { da inscrição } \\
\text { Perfurocortante. } \\
\text { A montagem do } \\
\text { recipiente deve ser feita } \\
\text { de forma precisa, com } \\
\text { auxílio do farmacêutico } \\
\text { na primeira compra. }\end{array}$} & \multirow[t]{2}{*}{$\begin{array}{l}\text { BRASIL, } \\
2004 .\end{array}$} \\
\hline $\begin{array}{l}\text { 2. Seu estabelecimento revende recipientes para } \\
\text { coleta de seringas e agulhas para diabéticos? }\end{array}$ & & \\
\hline 3. Qual o custo deste recipiente para o usuário? & & \multirow{2}{*}{$\begin{array}{l}\text { BRASIL, } \\
2018 .\end{array}$} \\
\hline $\begin{array}{l}\text { 4. Você costuma orientar (no momento da venda } \\
\text { de insulina) a aquisição do recipiente de coleta de } \\
\text { resíduo E? }\end{array}$ & & \\
\hline $\begin{array}{l}\text { 5. Qual a venda mensal de recipientes para } \\
\text { descarte de resíduo E (perfurocortante } \\
\text { contaminante)? }\end{array}$ & & $\begin{array}{l}\text { BRASIL, } \\
2005 .\end{array}$ \\
\hline 6. O recipiente é vendido montado? & & \\
\hline $\begin{array}{l}\text { 7. O usuário de insulina é orientado na forma de } \\
\text { preparo do recipiente, após o preenchimento? }\end{array}$ & & CENTER, \\
\hline $\begin{array}{l}\text { 8. Sua empresa participa do recolhimento do } \\
\text { recipiente após a coleta pelo usuário de insulina? }\end{array}$ & & \\
\hline $\begin{array}{l}\text { 9. Sua empresa orienta o usuário quanto à forma } \\
\text { correta de descarte? }\end{array}$ & & \\
\hline $\begin{array}{l}\text { 10.Sua empresa fornece o endereço de UBS } \\
\text { como pontos de coleta do recipiente? }\end{array}$ & & \\
\hline
\end{tabular}

Continua... 
...continuação.

\begin{tabular}{|c|c|c|}
\hline Roteiro de perguntas UBS & Pressupostos teóricos & Referências \\
\hline $\begin{array}{l}\text { 1. Seu posto fornece insulina para diabéticos tipo } \\
\text { 1? }\end{array}$ & \multirow{9}{*}{$\begin{array}{l}\text { A montagem incorreta } \\
\text { da caixa coletora } \\
\text { aumenta o risco. } \\
\text { A frequência de caixas } \\
\text { coletoras erroneamente } \\
\text { montadas, expõe os } \\
\text { profissionais a riscos } \\
\text { acidentais. } \\
\text { Competências do } \\
\text { técnico de enfermagem } \\
\text { em protocolos de } \\
\text { biossegurança e } \\
\text { compreensão do } \\
\text { manejo de } \\
\text { perfurocortantes. }\end{array}$} & \multirow{4}{*}{$\begin{array}{l}\text { LOPES et } \\
\text { al., } 1999 . \\
\text { MOURA et } \\
\text { al., 2009. }\end{array}$} \\
\hline $\begin{array}{l}\text { 2. Se sim, costuma oferecer o recipiente de coleta } \\
\text { de resíduo E? }\end{array}$ & & \\
\hline 3. O recipiente é oferecido já montado? & & \\
\hline $\begin{array}{l}\text { 4. Sua unidade orienta o usuário quanto à forma } \\
\text { correta de montagem do recipiente de descarte? }\end{array}$ & & \\
\hline $\begin{array}{l}\text { 5. O usuário de insulina é orientado na forma de } \\
\text { descarte do recipiente após o preenchimento? }\end{array}$ & & \multirow[t]{5}{*}{$\begin{array}{l}\text { BRASIL, } \\
1999 .\end{array}$} \\
\hline $\begin{array}{l}\text { 6. Seu posto faz o recolhimento do recipiente no } \\
\text { domicílio, após visitação de profissional de saúde } \\
\text { da ESF? }\end{array}$ & & \\
\hline $\begin{array}{l}\text { 7. Seu posto faz campanha de recolhimento do } \\
\text { recipiente para divulgação aos usuários de } \\
\text { insulina? }\end{array}$ & & \\
\hline $\begin{array}{l}\text { 8. Seu posto fornece o endereço de pontos de } \\
\text { revenda como farmácias e drogarias? }\end{array}$ & & \\
\hline $\begin{array}{l}\text { 9. Faça alguma observação sobre o tema da } \\
\text { entrevista. }\end{array}$ & & \\
\hline Roteiro de perguntas para diabéticos tipo I & \multirow{11}{*}{$\begin{array}{l}\text { Os indivíduos que } \\
\text { aplicam insulina em } \\
\text { casa são geradores de } \\
\text { resíduos sólidos de } \\
\text { saúde. }\end{array}$} & Referências \\
\hline $\begin{array}{l}\text { 1. Se faz uso de insulina, como procede (em } \\
\text { ambiente doméstico, posto, autoaplicação, outra } \\
\text { pessoa aplica)? }\end{array}$ & & \multirow{7}{*}{$\begin{array}{l}\text { PAULA et al., } \\
2014 . \\
\\
\text { BRUNNER; } \\
\text { SUDDARTH, } \\
2005 .\end{array}$} \\
\hline $\begin{array}{l}\text { 2. Como e com que frequência controla a glicemia } \\
\text { (com aparelho e lancetas)? }\end{array}$ & & \\
\hline 3. Como adquire seringas e lancetas ? & & \\
\hline 4. Quantas seringas e lancetas utiliza ao mês? & & \\
\hline $\begin{array}{l}\text { 5. Faz acompanhamento médico privado ou no } \\
\text { sistema público? }\end{array}$ & & \\
\hline $\begin{array}{l}\text { 6. Você utiliza ou já foi orientado a usar uma caixa } \\
\text { de descarte padrão ABNT (amarela), como a } \\
\text { adquire? }\end{array}$ & & \\
\hline $\begin{array}{l}\text { 7. Se não usa a caixa de descarte, como procede } \\
\text { ao descarte domiciliar de seringas agulhadas e } \\
\text { lancetas? }\end{array}$ & & \\
\hline $\begin{array}{l}\text { 8. Se você está fora de casa e usa insulina, como } \\
\text { procede com a seringa? }\end{array}$ & & 009. \\
\hline $\begin{array}{l}\text { 9. Você atualmente reside em casa (própria ou } \\
\text { alugada), apartamento (próprio ou alugado), outro } \\
\text { tipo de moradia (hotel, pensão, flat)? }\end{array}$ & & \\
\hline $\begin{array}{l}\text { 10. Quanto às orientações em como descartar seu } \\
\text { resíduo de seringas, agulhas e lancetas usadas, as } \\
\text { recebeu de quem? }\end{array}$ & & \\
\hline
\end{tabular}

Revbea, São Paulo, V. 14, № 1: 186-206, 2019. 
As respostas livres e observações foram analisadas por meio da técnica de análise de conteúdo, que de acordo com Bardin (2011) é um conjunto de técnicas que utiliza procedimentos sistemáticos para garantir uma descrição objetiva do conteúdo dos dados.

\section{Resultados e discussão}

\section{Papel educativo dos profissionais de farmácias e drogarias}

A Educação Ambiental se fortalece como um dos instrumentos para a construção de saberes, valores e práticas que pode ser trabalhada em espaços formais e não formais em parceria com os diversos ramos da sociedade (PONTES; FARIAS, 2016). No presente estudo, foi observado que $87,2 \%$ dos estabelecimentos visitados não vendem a caixa padrão ABNT de descarte, até mesmo nos estabelecimentos que comercializam a insulina (84,2\%). Apenas dez estabelecimentos $(4,25 \%)$ comercializam o recipiente padrão para resíduo $\mathrm{E}$, já montado, para seus clientes diabéticos e $30(13,6 \%)$ revendem sem montar a caixa coletora, no momento da aquisição de insulina. O valor encontrado do recipiente variou entre $R \$ 3,50$ (pequeno) a 18,00 reais (grande), mas apenas uma farmácia orienta os clientes diabéticos e recolhe o resíduo gerado pelos mesmos, em caixa padrão ABNT. Os farmacêuticos parecem concordar que recolher o resíduo $\mathrm{E}$ de clientes geraria um custo adicional para a empresa, pois os alguns estabelecimentos não aplicam mais injeções e, por isso, o serviço pago de empresas coletoras de RSS foi suspenso, como sugere um dos responsáveis técnicos (RT1):

RT1- Quando a farmácia prestava esse tipo de serviço de aplicar injeções, não era problema recolher seringas de clientes. Hoje não fazemos mais, então não tem porque recolher esse resíduo. O que fazemos quando o cliente pergunta, é orientar para guardar em garrafa plástica de refrigerante e levar em "postinho" (SIC).

Embora a Lei o 13021 (BRASIL, 2014) permita que as farmácias apliquem medicamentos injetáveis e vacinas, alguns estabelecimentos de pequeno porte preferem não prestar esse tipo de serviço, pelos custos de ajustar as instalações (segundo normas sanitárias) e custo com empresas terceirizadas que recolhem os RSS, como apontado pelo RT2:

RT2- Optamos por não montar sala de vacina e injetáveis, pois seria custoso e teríamos que readequar o local. Mesmo se tivéssemos, pra recolher os resíduos de clientes, pagaríamos por peso extra para a empresa coletora e isso aumentaria os gastos da farmácia. 
Como visto, embora a revenda de insulina e seringas para aplicação, seja uma prática do comércio varejista estudado, grande parte dos farmacêuticos ainda não reconhece seu papel educacional em apoio ao diabético na segregação adequada de resíduos do tipo $\mathrm{E}$ domésticos, por motivos econômicos. Por isso, as respostas em sua maioria são negativas quanto à indicação de pontos de descarte (como UBS), se revende a caixa padrão ou coletor, se sugere a compra da caixa ao cliente no momento da aquisição de insulina, se orienta quanto ao preparo ou montagem da caixa coletora, se orienta após o preenchimento e se participa do recolhimento, como demonstrado na Figura 1.

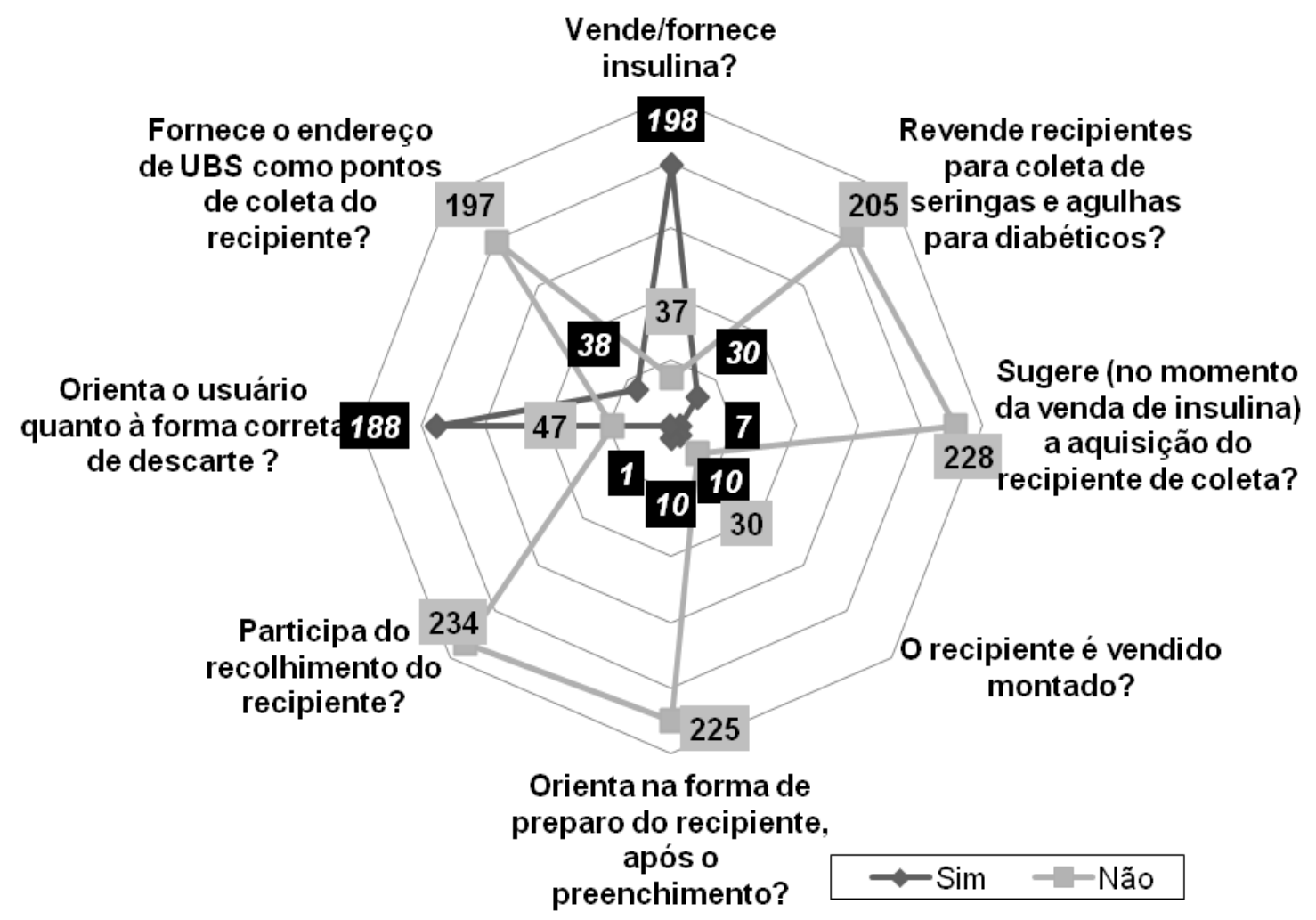

Figura 1: Respostas coletadas dos responsáveis técnicos farmacêuticos.

Mesmo os estabelecimentos que não fornecem o recipiente e nem vendem insulina $(n=197), 80 \%$ dos respondentes farmacêuticos afirmaram prestar informações educacionais sobre a correta segregação das seringas agulhadas após o uso de insulina, porém, para alguns respondentes, a interpretação de "correto" foi orientar erroneamente o recolhimento em garrafas plásticas e encaminhar para postos de saúde, como demonstrado na fala do RT3: 
RT3- Quando o cliente diabético pergunta se pode trazer as seringas para a gente descartar, orientamos a acumular numa garrafa plástica de refrigerante e levar num posto de ou hospital perto da casa dele.

\section{Papel dos profissionais de saúde em UBS}

No município de São Paulo, as Unidades Básicas de Saúde (UBS) possuem os serviços mais capacitados a tratar de doentes crônicos como cardíacos e diabéticos, além de realizar atendimentos gratuitos típicos de medicina preventiva e serviços como fornecimento de medicação básica. A UBS é o contato preferencial dos usuários, a principal porta de entrada e centro de comunicação com toda a Rede de Atenção à Saúde. É instalada perto de onde as pessoas moram, trabalham, estudam e vivem e, com isso, desempenha um papel central na garantia de acesso à população a uma atenção à saúde de qualidade (BRASIL, 2017).

Portanto, para a assistência aos diabéticos, a UBS é o principal polo de apoio, onde o paciente tem acompanhamento médico e recebe a insulina pelo Sistema Único de Saúde (SUS). Os resultados apontaram que das 70 UBS, $98,6 \%$ forneciam insulina para diabéticos $(n=69)$, porém $32(45,7 \%)$ das UBS ofereciam a caixa coletora e dentre estas, $16(50 \%)$ já ofereciam o recipiente montado e $13(40 \%)$ orientavam sobre o procedimento de montagem (Figura 2).

Fornece insulina para diabéticos?

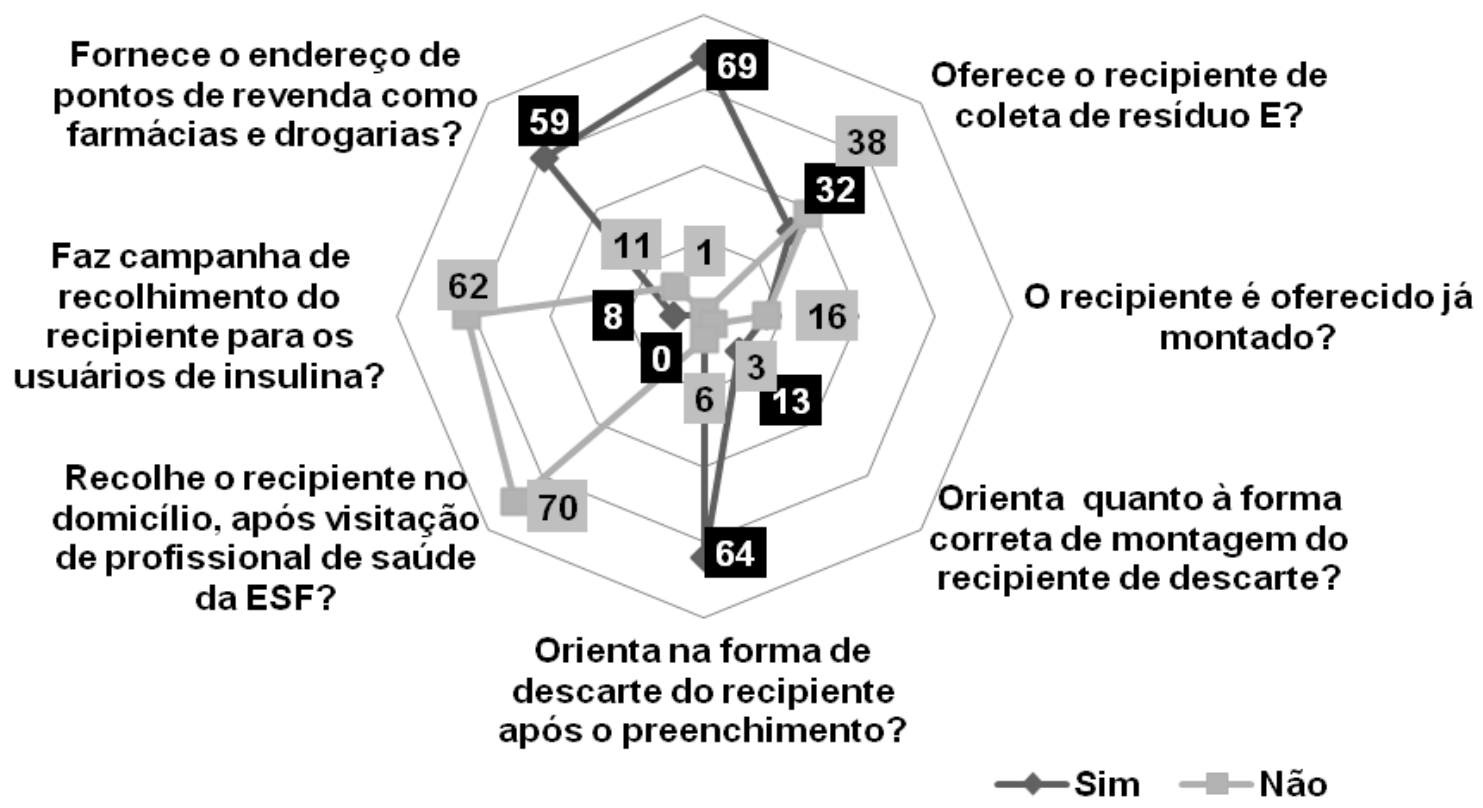

Figura 2: Respostas coletadas dos responsáveis pela UBS 
Observa-se que as respostas negativas (68) se referem às campanhas educacionais de recolhimento de resíduos, como educação continuada aos diabéticos e recolhimento pelas equipes de Estratégia de Saúde da Família (ESF) dos recipientes que estariam preenchidos nos domicílios visitados. A busca e recolhimento do recipiente por um auxiliar de enfermagem ou um agente comunitário de saúde não é atribuição destes profissionais, segundo as competências dos membros das equipes de ESF (JUNQUEIRA, 2008).

Dos profissionais da UBS, $64(91,4 \%)$ afirmaram que orientavam quanto ao descarte final do recipiente e, em geral, é solicitado que tragam de volta para a própria UBS de onde retiram a insulina e seringas. Na questão aberta, é possível verificar que nem sempre o recipiente de coleta retorna à UBS, segundo a fala de uma enfermeira (E):

E- Fornecemos a caixa coletora, mas nem todo mundo traz de volta, alguns trazem em garrafas de refrigerante. Isso dificulta nosso trabalho, pois temos que cortar a garrafa pra jogar numa caixa Descarpak (SIC) maior, porque a empresa de lixo hospitalar não aceita garrafa PET e aí tem o perigo da contaminação. Algumas garrafas estão até quebradiças e podem nos expor ao risco de furar os dedos.

\section{Respondentes diabéticos}

A grande parte dos respondentes mora em casa própria (63\%), indicando que a disposição do lixo comum se dá diretamente nas ruas. Foi observado que $87,27 \%$ dos diabéticos receberam orientação verbal sobre o descarte de resíduos perfurocortantes de profissionais de saúde, embora cerca de $4 \%$ nunca se preocupasse com isso e $8 \%$ desconheciam a correta segregação, como demonstrado na Tabela 2.

Sobre os procedimentos no momento do descarte do resíduo perfurocortante, referentes aos diabéticos (123) que não utilizam caixa coletora padrão, está representado na Figura 3, onde é possível observar que 49,6\% reencapa a agulha e joga na garrafa PET, enquanto que $33,3 \%$ reencapando ou não, descartam diretamente no lixo. 
Tabela 2: Respostas dos diabéticos entrevistados

\begin{tabular}{|c|c|c|c|}
\hline Roteiro & \multicolumn{3}{|c|}{$\begin{array}{l}\text { Respostas } \\
\text { n (\%) }\end{array}$} \\
\hline \multirow{2}{*}{$\begin{array}{l}\text { 1. Se faz uso de insulina, } \\
\text { como procede (na residência, } \\
\text { posto, autoaplicação, outra } \\
\text { pessoa)? }\end{array}$} & $\begin{array}{l}\text { Uso doméstico com } \\
\text { autoaplicação }\end{array}$ & $\begin{array}{l}\text { Uso doméstico } \\
\text { por outra pessoa }\end{array}$ & $\begin{array}{c}\text { Aplica em } \\
\text { postos de saúde }\end{array}$ \\
\hline & $126(57,2 \%)$ & $76(34,5 \%)$ & $18(8,1 \%)$ \\
\hline \multirow{2}{*}{$\begin{array}{l}\text { 2. Controla a glicemia (com } \\
\text { aparelho e lancetas) em } \\
\text { domicílio? }\end{array}$} & $\begin{array}{l}\text { Frequentemente } \\
\text { para aplicar } \\
\text { insulina }\end{array}$ & $\begin{array}{l}\text { Controlo } \\
\text { raramente em } \\
\text { casa }\end{array}$ & $\begin{array}{l}\text { Controlo no } \\
\text { posto de saúde }\end{array}$ \\
\hline & $160(72,2 \%)$ & $52(23,6 \%)$ & $8(3,6 \%)$ \\
\hline \multirow{2}{*}{$\begin{array}{l}\text { 3. Como adquire seringas e } \\
\text { lancetas? }\end{array}$} & Postos de Saúde & $\begin{array}{l}\text { Redes de } \\
\text { farmácias }\end{array}$ & Ambas \\
\hline & 185 (84\%) & $33(15 \%)$ & $2(0,9 \%)$ \\
\hline \multirow{2}{*}{$\begin{array}{l}\text { 4. Se faz uso de seringa e } \\
\text { lancetas, quantas utiliza ao } \\
\text { mês? }\end{array}$} & Mais de 30 por mês & $\begin{array}{c}\text { De } 21 \text { a } 25 \text { por } \\
\text { mês }\end{array}$ & $\begin{array}{c}\text { De } 10 \text { a } 15 \text { por } \\
\text { mês }\end{array}$ \\
\hline & $178(80,9 \%)$ & $37(16,8 \%)$ & $5(2,3 \%)$ \\
\hline \multirow{2}{*}{$\begin{array}{l}\text { 5. Faz acompanhamento } \\
\text { médico privado ou no sistema } \\
\text { público? }\end{array}$} & Privado & Público & \\
\hline & $68(30,9 \%)$ & $152(69 \%)$ & \\
\hline \multirow{2}{*}{$\begin{array}{l}\text { 6. Você utiliza a caixa de } \\
\text { descarte padrão ABNT } \\
\text { (amarela), como a adquire? }\end{array}$} & Nunca adquiro & $\begin{array}{l}\text { Adquiro nos } \\
\text { postos com } \\
\text { pedido médico }\end{array}$ & $\begin{array}{l}\text { Adquiro nos } \\
\text { postos sem } \\
\text { pedido médico }\end{array}$ \\
\hline & $123^{*}(60 \%)$ & $81(36,8 \%)$ & $16(7,3 \%)$ \\
\hline \multirow{2}{*}{$\begin{array}{l}\text { 7. } \quad \text { *Se não usa a caixa de } \\
\text { descarte, como procede ao } \\
\text { descarte de seringas agulhadas } \\
\text { e lancetas? }\end{array}$} & $\begin{array}{l}\text { Joga no lixo } \\
\text { comum }\end{array}$ & $\begin{array}{c}\text { Guarda em } \\
\text { garrafas tipo PET }\end{array}$ & \\
\hline & $100^{*}(81,3 \%)$ & $23^{*}(18,7 \%)$ & \\
\hline \multirow{2}{*}{$\begin{array}{l}\text { 8. Se você está fora de casa e } \\
\text { usa insulina, como procede com } \\
\text { a seringa? }\end{array}$} & $\begin{array}{c}\text { Guarda para jogar } \\
\text { em casa }\end{array}$ & $\begin{array}{l}\text { Joga no lixo } \\
\text { comum }\end{array}$ & $\begin{array}{l}\text { Não soube } \\
\text { responder }\end{array}$ \\
\hline & $87(39,5 \%)$ & $132(60 \%)$ & $1(0,4 \%)$ \\
\hline \multirow{2}{*}{$\begin{array}{l}\text { 9. Você atualmente reside em } \\
\text { casa apartamento, outro tipo de } \\
\text { moradia (hotel, pensão, flat)? }\end{array}$} & $\begin{array}{l}\text { Casa própria / } \\
\text { alugada }\end{array}$ & $\begin{array}{l}\text { Apto próprio/ } \\
\text { alugado }\end{array}$ & $\begin{array}{l}\text { Outro (pensão, } \\
\text { hotel, flat, etc.) }\end{array}$ \\
\hline & $140(63 \%) / 30(13 \%)$ & $20(9 \%) / 30(13 \%)$ & 0 \\
\hline \multirow[t]{2}{*}{$\begin{array}{l}\text { 11. Quanto às orientações em } \\
\text { como descartar seu resíduo, } \\
\text { as recebeu de quem? }\end{array}$} & $\begin{array}{l}\text { Recebeu } \\
\text { verbalmente de } \\
\text { profissional de } \\
\text { saúde }\end{array}$ & $\begin{array}{l}\text { Nunca se } \\
\text { preocupou com } \\
\text { isso }\end{array}$ & $\begin{array}{l}\text { Nunca recebeu } \\
\text { orientação }\end{array}$ \\
\hline & $192(87,2 \%)$ & $10(4,5 \%)$ & $18(8,1 \%)$ \\
\hline
\end{tabular}




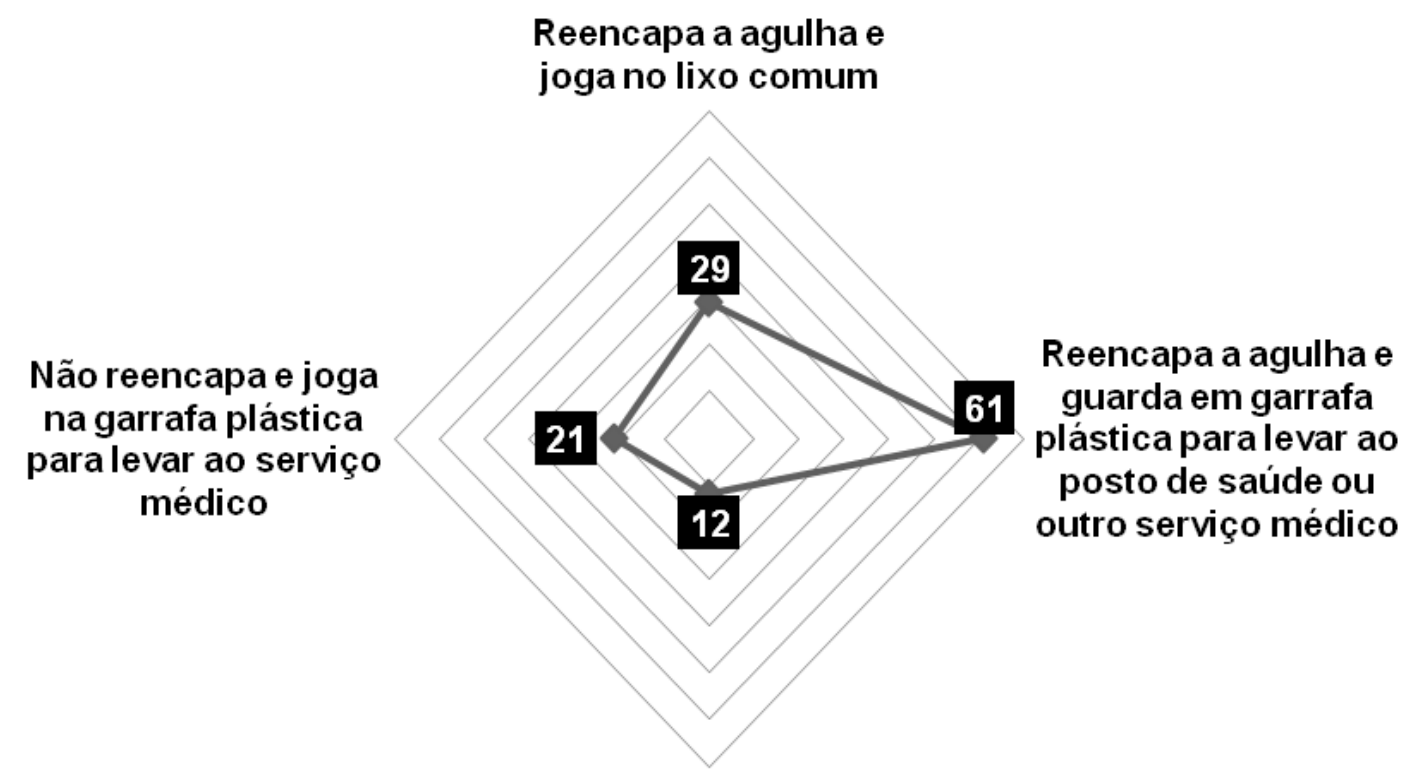

Não reencapa, quebra ou dobra a agulha e joga no lixo comum

Figura 3: Procedimentos (\%) ao descartar resíduos sem caixa coletora

Dos diabéticos respondentes, $80 \%$ usam as seringas e lancetas de controle glicêmico (entre 10 a 30 lancetas por mês) e 60\% afirma não adquirir a caixa coletora em postos de saúde ou comprando em redes de farmácias. Dentre estes, $81 \%$ afirma jogar os resíduos $\mathrm{E}$ no lixo comum. O presente estudo ainda demonstrou que $44 \%$ dos diabéticos que buscam a caixa coletora em postos de saúde, o fazem com ou sem solicitação médica. Dos que não adquirem a caixa padrão, 18,7\% recolhe em garrafas do tipo PET.

Uma pesquisa realizada no Ceará com usuários de insulina revelou que $86 \%$ da população estudada referiram descartar as seringas junto com resíduos comuns, $11 \%$ as enterravam no quintal e apenas $2 \%$ as encaminhavam aos serviços de saúde (FERREIRA et al., 2009).

A prática de descartar seringas e lancetas em garrafas ou jogar diretamente no lixo comum coloca em risco não apenas profissionais da área de saúde, mas também o coletor de lixo urbano. De acordo com Dias e colaboradores (2015) em uma sociedade tão desenvolvida ainda encontra-se desigualdades e deficiências, principalmente quando se refere à educação, orientação e cultura de segurança no trabalho e o reconhecimento da importância da conduta e de práticas de segurança em muitas áreas ainda precisa amadurecer os seus objetivos e métodos, para atingir a realização das diversas atividades sem danos para saúde e integridade do colaborador. Ainda o autor ressalta que o coletor (catador de lixo) é muito exposto a esse risco devido ao constante contato com os resíduos contendo agentes biológicos de 
doenças infectocontagiosas (leptospirose, difteria, tifo), entre outros. Os microrganismos patogênicos estão presentes nos resíduos sólidos municipais, principalmente, em lenços de papel, curativos, fraldas descartáveis, papel higiênico, absorventes, seringas descartáveis com agulhas, camisinhas e RSS misturados aos resíduos comuns.

Pesquisadores ingleses levantaram o tipo de descarte dado para seringas usadas por usuários de insulina em Londres, e concluíram que a maioria da população estudada utilizava caixa de perfurocortantes para o descarte das seringas; esse estudo também enfatizava a necessidade da aquisição de dispositivos seguros para o descarte de materiais perfurocortantes em domicílio (CRAWSHAW et al., 2002). Quanto ao acondicionamento, os autores reportaram que seringas e agulhas $(65,2 \%)$ e lancetas $(52,2 \%)$ eram acondicionadas também em garrafas plásticas.

André (2012) demonstrou que a maioria dos entrevistados informou realizar o descarte de seringas e agulhas $(57,8 \%)$ e lancetas $(53,8 \%)$ em garrafas plásticas, encaminhando, posteriormente, para algum serviço de saúde. No presente estudo, dos 123 respondentes diabéticos que usam insulina fora do ambiente doméstico, cerca de $60 \%$ descarta em lixo comum, não se preocupando com a destinação final do resíduo perfurocortante gerado também fora de seus domicílios. O autor apontou que em relação às orientações recebidas para o manejo e descarte desses resíduos, $61,5 \%$ dos sujeitos afirmaram ter recebido algum tipo de orientação de algum serviço de saúde. Já no presente estudo, $81 \%$ dos diabéticos afirmaram ter recebido orientação quanto ao resíduo $\mathrm{E}$ gerado no autocuidado.

Segundo Paula et al. (2014), o coletor deve ser acondicionado em local seco e arejado, longe do alcance de animais e crianças. A montagem deve ser feita de forma precisa e o coletor nunca pode estar cheio, ele só deve ser completado até a marca pontilhada indicativa de volume na caixa. Seu transporte deve ser feito pela alça e nunca pelo fundo da caixa. Quando a marca limite de preenchimento for atingida, ele deve ser fechado e colocado dentro de um saco plástico e entregue no posto de saúde mais próximo. Este coletor é encaminhado ao serviço de Coleta de Resíduos de Serviço da Saúde, no qual recebe tratamento não provocando risco para a saúde da população nem ao meio ambiente. Porém, ao que tudo indica, a dificuldade no manejo da caixa coletora é o maior obstáculo ao diabético. Foi observado em algumas das falas dos entrevistados diabéticos (D) que apesar da caixa ser disponível desmontada, havia dificuldade na montagem:

D - Às vezes falta a caixa no posto e sou orientado a trazer em garrafa PET. Até prefiro juntar e levar as seringas e lancetas em garrafas grandes, pois demora mais tempo pra levar (sic). Demorei pra aprender a montar a caixa de papelão e até hoje acho complicado montar. 
A mesma percepção foi observada por uma auxiliar de enfermagem, demonstrando que até mesmo estes profissionais têm dificuldade de montar a caixa coletora. Paula et al. (2014) ressaltaram que em caso de dúvida, o diabético deve pedir ao farmacêutico fazer a montagem da caixa coletora na primeira compra e, na próxima compra fazer o inverso, montar com a supervisão do mesmo. Entretanto, como apontado por este estudo, a caixa coletora não é encontrada com facilidade no mercado varejista farmacêutico e o responsável técnico pode não representar um profissional de apoio educacional para esta questão.

Nesse contexto, é importante chamar a atenção dos profissionais de saúde para a necessidade de reforçar as orientações aos usuários de insulina, em face dos riscos oriundos de práticas inadequadas do descarte de resíduos perfurocortantes e de outros perigosos. Nesse cenário, os gestores também devem apoiar e implantar programas de educação em saúde nos serviços destinados a esses usuários e ainda fornecer recipientes adequados para o descarte dos RSS gerados em domicílios (ANDRÉ et al., 2012). Tais medidas garantem a segurança dos colaboradores da área de saúde, visto que a Norma Regulamentadora (NR) № 09, o Ministério do Trabalho e Emprego (MTE) dispõe sobre o Programa de Prevenção de Riscos Ambientais. Esse programa é a principal ferramenta no que diz respeito à prevenção, pois ele não se trata somente de um documento, mas por ser um programa, ele é interativo e não engessado (DIAS et al., 2015).

\section{Considerações finais}

Existe uma inadequação na educação sobre o manejo e descarte dos resíduos oriundos do tratamento e monitoramento de diabéticos em domicílio, sendo o destino de materiais como fitas reagentes (com sangue), lancetas, seringas e agulhas usadas descartados em lixo doméstico comum ou em garrafas plásticas (PET), encaminhando, posteriormente, para algum serviço de saúde. A falta de padronização do gerenciamento de descarte do RSS domiciliar e a mistura com o lixo doméstico faz com que esse material seja descartado em aterros sanitários, oferecendo riscos à saúde da população e ao meio ambiente.

Os serviços de assistência à saúde também não trabalham de forma padronizada, frente às orientações quanto aos cuidados de descarte de agulhas, seringas e lancetas utilizadas em domicílio. O modo recomendado seria fazê-lo em recipientes de papelão, conforme padrão ABNT ou, na falta desses, em recipientes rígidos, com abertura larga e tampa (BRASIL, 2004; 2018). Ainda se observa o uso Inadequado de garrafas de plástico no transporte destes resíduos.

Um caminho em comum para solucionar a questão deste RSS é a educação continuada e treinamento dos profissionais de saúde, além do esclarecimento junto à população. Diante disso Castro et al. (2000) já apontavam a relevância em problematizar essa questão, em um entendimento de que, para implantar técnicas de gerenciamento de resíduos nas diferentes fontes 
geradoras da área da saúde, faz-se necessário um investimento em educação para todos os profissionais que atuam nos âmbitos da saúde, de forma a prepará-los e instrumentalizá-los para lidar com essa questão.

O diabético necessita de apoio material, orientação e educação sobre a melhor maneira de dispor seu resíduo, não apenas em ambiente doméstico, mas externamente como foi demonstrado (nas ruas ou em seu local de trabalho). A UBS ainda é o ponto estratégico de apoio, apesar das inúmeras dificuldades do sistema público de saúde, porém, ainda existe uma lacuna de $30 \%$ dos diabéticos que não utilizam o SUS, mas que precisam da aquisição de caixas coletoras em redes privadas de farmácia e drogarias que, em sua maioria, sequer revende o produto.

O resultado disso é a disposição dos resíduos jogados diariamente no lixo comum, colocando em risco a população em geral. Armazenar resíduos em garrafas PET também não é uma boa prática, visto o risco ocupacional de profissionais de saúde e, faz-se necessário uma interligação dos stakeholders envolvidos como os da rede varejista farmacêutica, sistema público e privado de saúde, além dos próprios diabéticos, no gerenciamento de seu resíduo $E$, que na verdade, deveria ser compartilhada com todos. A tomada de medidas, no contexto da biossegurança, aliando recursos materiais, campanhas de conscientização, preservação do meio ambiente, ética e responsabilidade, poderá garantir mais qualidade de vida no presente e um futuro mais saudável para o meio ambiente, profissionais de saúde e população em geral, onde estão inclusos os próprios diabéticos.

\section{Referências}

AMERICAN DIABETES ASSOCIATION. Clinical Practice Recommendations. 2007. Disponível em: <https://professional.diabetes.org/>. Acesso em 13 mar. 2014.

AGÊNCIA NACIONAL DE VIGILÂNCIA SANITÁRIA/ MINISTÉRIO DA SAÚDE. Manual de gerenciamento de resíduos de serviços de saúde. - Brasília: Ministério da Saúde -Série A. Normas e Manuais Técnicos. ISBN 85-334-11766, 2006, $182 \mathrm{p}$.

ANDRÉ, S.C.S. Resíduos Gerados em Domicílios de Indivíduos com Diabetes Mellitus, Usuários de Insulina. Revista Baiana de Saúde Pública, v. 36, n. 4, 2012.

ANDRÉ, S.C.S.; MENDES, A.A.; RIBEIRO, T.M.L.; SANTOS, A.P.M.; VEIGA, T.B.; TAKAYANAGUI, A.M.M. Resíduos gerados por usuários de insulina em domicílio: proposta de protocolo para unidades de saúde. Ciência, Cuidados e Saúde, v.11, n. 4, 2012.

ASSOCIAÇÃO BRASILEIRA DE NORMAS TÉCNICAS. NBR 12.807: Resíduos de Serviços de Saúde - Terminologia. Rio de Janeiro, ABNT, 1993, 3 p. 
ASSOCIAÇÃO BRASILEIRA DE NORMAS TÉCNICAS. NBR 10004: Resíduos Sólidos - Classificação. 2 ed. Rio de Janeiro, ABNT, 2004. Disponível em:<http://www.unaerp.br/documentos/2234-abnt-nbr-10004/file> Acesso em: 10 de março de 2017.

AZEVEDO. L.V.; ALEXANDRINO, S.A.; DA SILVA, J.L.M; COSTA, D.R.T.R. Educação ambiental e legislação: reflexões sobre participação e efetividade. Revista Brasileira de Educação Ambiental - Revbea, São Paulo, v. 12, n. 2, p. 284-295, 2017.

BARBOSA, L.M.M. Glossário de epidemiologia e saúde. In: Rouquayrol, M.Z.; Filho, A. (Org.). Epidemiologia e saúde. 5 ed. Rio de Janeiro: Medsi, 1999. p. 523-598.

BARDIN, L. Análise de conteúdo. São Paulo: Almedina, 2011.

BRASIL. AGÊNCIA NACIONAL DE VIGILÂNCIA SANITÁRIA (ANVISA). Resolução da Diretoria Colegiada - RDC no 306 de 07 de dezembro de 2004. Dispõe sobre o regulamento técnico para o gerenciamento de Resíduos de Serviços de Saúde. Diário Oficial [da República Federativa do Brasil]. Disponível em:, http://bvsms.saude.gov.br/bvs/saudelegis/anvisa/2004/res $0306 \quad 07 \quad 12$ 2004.html.> Acesso em: 13 de março de 2017.

BRASIL. AGÊNCIA NACIONAL DE VIGILÂNCIA SANITÁRIA (ANVISA). Resolução da Diretoria Colegiada - RDC no 222 de 28 de março de 2018. Regulamenta as Boas Práticas de Gerenciamento dos Resíduos de Serviços de Saúde e dá outras providências. Diário Oficial [da República Federativa do Brasil]. Disponível em: http://bvsms.saude.gov.br/bvs/saudelegis/anvisa/2004 /res0306 0712 2004.html.> Acesso em: 10 de maio de 2018.

BRASIL. Conselho Nacional do Meio Ambiente. Resolução no 358, de 29 de abril de 2005. Diário Oficial [da República Federativa do Brasil]. Brasília, n. 84, Seção I, 4 mai. 2005. p.63-65.

BRASIL. Ministério da Saúde. Diretrizes Curriculares Nacionais para o Ensino Técnico Área da Saúde. Diário Oficial [da República Federativa do Brasil], Brasília (DF); 1999. Disponível em: <https://www.opas.org.br/.> Acesso em: 23 de março de 2017.

BRASIL. Ministério do Planejamento. PAC. UBS - Unidade Básica De Saúde 2017. Disponivel em: <http://www.pac.gov.br/infraestrutura-social-e-urbana/ubsunidade-basica-de-saude>. Acesso em: 23 de março de 2017.

BRASIL. Presidência da República Lei ㄲo 13.021, de 8 de agosto de 2014. Dispõe sobre o exercício e a fiscalização das atividades farmacêuticas. Diário Oficial [da República Federativa do Brasil] Disponível em: <http://www.planalto.gov.br/ccivil 03/ Ato2011-2014/2014/Lei/L13021.htm.>. Acesso em: 12 de março de 2017. 
BRASIL. Presidência da República. Lei № 12.305, de 3 de agosto de 2010. Dispõe sobre a Política Nacional de Resíduos Sólidos. Diário Oficial [da República Federativa do Brasil]. Disponível em: <http://www.planalto.gov.br/ ccivil 03/ ato2007-2010/2010/lei/l12305.htm.> Acesso em: 17 de março de 2017.

BRASIL. Presidência da República. Lei ํo 9.605, de 12 de fevereiro de 1998. Dispõe sobre as sanções penais e administrativas derivadas de condutas e atividades lesivas ao meio ambiente, e dá outras providências. Diário Oficial [da República Federativa do Brasil], Disponível em: <http://www.planalto.gov.br/ ccivil 03/leis/L9605.htm. . . Acesso em: 10 de março de 2017.

BRUNNER, L.S; SUDDARTH, D.S. Tratado de Enfermagem Médico Cirúrgica. 10 ed. Rio de Janeiro: Guanabara Koogan, 2005, 2419 p.

CRAWSHAW, G.; IRWIN, D.J.; BUTTON, J. Disposal of syringes, needles, and lancets used by diabetic patients in North East Essex. Communicable Disease and Public Health, v. 5, n. 2, p.134-137, 2002.

CUSSIOL, N.A.M; ROCHA; G.H.T.; LANGE, L.C. Quantificação dos resíduos potencialmente infectantes presentes nos resíduos sólidos urbanos da regional sul de Belo Horizonte, Minas Gerais, Brasil. Cadernos de Saúde Pública, v. 22, n. $6,2006$.

Diabetic Center. Educação em diabetes: Descarte consciente de resíduos perfuro-cortante domiciliares, 2015. Disponível em: <http://www.diabetescenter. com.br/portaldiabetes/descarte-consciente-deesiduos-perfuro-cortantedomiciliares-2/.>Acesso em: 18 de abril de 2017.

DIAS, A. G.; MATOS, R.F.; BRAGA, D. L. C.; MAGOSSI, A.; DINIZ, A. C.; ANTONIO, L.S. Riscos ocupacionais em atividade de coleta de resíduos sólidos. Engineering and Science, v. 1, n. 3, p. 3-17, 2015.

FERREIRA, C.D.; DAMASCENO, C.F., REBELLO, M.M.C.B,; SANTOS, M.F.; SOBRINHA, M.F.; ALVES, M.D.S.; CONCEIÇÃO, M.R. Diabetes Mellitus e o descarte de seringas no domicílio: consciência ambiental. In: 61ํ CONGRESSO BRASILEIRO DE ENFERMAGEM. Anais...Fortaleza: ABEn., 2009, p. 4120-3.

GODOI, C.K.; BALSINI, C.P.V. A pesquisa qualitativa nos estudos organizacionais brasileiro: uma análise bibliométrica. In: GODOI, C.K.; BANDEIRA-DE-MELLO, R.; SILVA, A. B. da (Org.). Pesquisa, estratégia e métodos. 2 ed. São Paulo: Saraiva, 2010. cap. 2, p. 53-87.

JUNQUEIRA, S. R. Competências profissionais na estratégia Saúde da Família e o trabalho em equipe. Módulo Político Gestor, 2008. Disponível em: <www. unasus.unifesp.br/biblioteca virtual/esf/1/modulo politico gestor/Unidade 9.pdf > Acesso em: 12 de abril de 2017.

LOPES, M.H.B.M.; MOROMIZATO, S.S.; VEIGA, J.F.F.S. Adesão às medidas de precaução-padrão: relato de experiência. Revista Latino-americana de Enfermagem, v.7, n. 4, p. 83-88, 1999. 
MAIA, F.F.R.; ARAÚJO, L.R. Aspectos psicológicos e controle glicêmico de um grupo de pacientes com Diabetes Mellitus tipo $1 \mathrm{em}$ Minas Gerais. Arquivos Brasileiros de Endocrinologia \& Metabologia. v. 48, n.2, 2004.

MAROUNM, C.A. Manual de Gerenciamento de Resíduos: Guia de procedimento passo a passo. SEBRAE. 2 ed. Rio de Janeiro: GMA-ISBM, 2006.

MOURA, E.C.C; MOREIRA M.F.S; FONSECA, S.M. Atuação de auxiliares e técnicos de enfermagem no manejo de perfurocortantes: um estudo necessário. Revista Latino-americana de Enfermagem, v.7, n. 3, 2009.

PAULA, L.M.F.; NOGUEIRA, L.T.C.; SILVA, R.P.P.; PAIXÃO, C.A.P. Destino do lixo perfurocortante produzido por insulinodependentes de um município mineiro, 2014. Disponível em:<www.fwb.edu.br/congressoic/resumos/resumo06.pd $>$ Acesso em: 5 de abril de 2017.

PONTES, L.G.D.F.; FARIAS, A.L.A. O desafio da gestão ambiental municipal: o caso do programa de educação ambiental de Belém. Revista Eletrônica do Mestrado em Educação Ambiental, v. 33, n.3, p. 302-319, 2016.

SILVA, E. H. Acondicionamento e destinação final dos resíduos sólidos de serviço de saúde gerados pelos portadores de Diabetes Mellitus, num bairro de Campina Grande-PB. In: CONGRESSO BRASILEIRO DE GESTÃO AMBIENTAL, 3, 2012, Goiania. Anais... Goiania, p. 1 - 6.

TAPIA, C.E.V. Diabetes Mellitus e o descarte de seringas e agulhas. Revista Gaúcha de Enfermagem, v. 30, n. 2, p. 228-234, 2009.

ZANETTI, M.L.; MENDES, I.A.C.; RIBEIRO, K.P. O desafio para o controle domiciliar em crianças e adolescentes diabéticas tipo 1. Revista Latinoamericana de enfermagem, v.9, n.4, p.32-36, 2001. 